\title{
Adoption of mobile information services: An empirical study
}

\author{
Shang $\mathrm{Gao}^{\mathrm{a}, *}$, John Krogstie ${ }^{\mathrm{b}}$ and Keng Siau ${ }^{\mathrm{c}}$ \\ ${ }^{a}$ School of Business Administration, Zhongnan University of Economics and Law, Wuhan, Hubei, China \\ ${ }^{\mathrm{b}}$ Department of Computer and Information Science, Norwegian University of Science and Technology, \\ Trondheim, Norway \\ ${ }^{\mathrm{c}}$ Department of Business and Information Technology, The Missouri University of Science and \\ Technology, Rolla, MO, USA
}

\begin{abstract}
This study investigates the adoption of mobile information services at a Norwegian university. By expanding the Technology Acceptance Model (TAM), a new research model, known as the mobile services acceptance model (MSAM), is proposed. Based on the research model, seven research hypotheses are presented. The proposed research model and research hypotheses were empirically tested using data collected from a survey of users of a mobile service, extended Mobile Student Information Systems (eMSIS), at a Norwegian university. The findings indicate that the fitness of the research model is good. Support was also found for the seven research hypotheses. Among the factors, the personal initiatives and characteristics has the strongest influence on the intention to use eMSIS.
\end{abstract}

Keywords: Trust, context, personal initiatives and characteristics, mobile services acceptance model

\section{Introduction}

Along with the popularity of mobile devices and advances in wireless technology, mobile services have become more and more prevalent. Although there are now a large number of services, the adoption of many advanced mobile services has been slower than expected [13]. A mobile service is a term used to describe software that runs on mobile devices. Mobile services are designed to educate, entertain, and assist users in their daily lives.

While there has been an increasing availability of mobile services, limited attention has been given to user adoption of mobile services, particularly with newly developed advanced mobile services (e.g., advanced software on mobile devices). For example, some advanced software on mobile devices is not a self-contained service, but an advanced service which needs to collect latest data from other information systems (e.g., eMSIS presented in Section 5.1). Prevalence of mobile services depends not only on technology advancement, but also on user adoption. The problem that we want to address in this research is to investigate students' reactions and attitude to an advanced mobile service in terms of a mobile service acceptance model.

\footnotetext{
${ }^{*}$ Corresponding author: Shang Gao, No.182 Nanhu Avenue, East Lake High-tech Development Zone, Wuhan 430073, Hubei, China. Tel.: +86 278838 6757; Fax: +86 278838 6757; E-mail: shangkth@ gmail.com.
} 
Building successful strategies for promoting mobile services stems from a good understanding of users' expectations and preferences on mobile services. Key factors for the success of mobile services are to identify the actual and potential customers, to investigate how they are influenced and how they behave (i.e., users' behavior), and to uncover what they really expect (i.e., needs, and preferences) [7]. Therefore, it is essential to understand the potential users and their requirements to develop mobile services [41]. In this study, we are not focusing on mobile services development techniques. Rather, we are interested in examining the effect of some potential factors on users' adoption intention in mobile services.

Based on analysis of prior literature on technology diffusion and acceptance of mobile services using existing technology acceptance theory, a research model, which is known as mobile services acceptance model in [26], was developed to investigate the adoption of mobile services. The mobile services acceptance model was derived by expanding the original Technology Acceptance Model (TAM) proposed by Davis [19], To operationalize the research model, a measurement instrument developed in [27] was used to measure each of the constructs. University students can be viewed as one of the major target markets of mobile services. Our specific interest in this study is to investigate students' perspectives on the adoption of mobile student information services at a Norwegian University.

The objective of this paper is to empirically examine how well the proposed research model is able to explain mobile information services adoption with a mobile service called eMSIS. eMSIS can be seen as an advanced mobile service since it is a mobile aggregation of a data from a number of other services related to the campus-wide information system. Details about eMSIS can be found in Section 5. The research model is analyzed using Partial Least Squares (PLS) analysis.

The remainder of this paper is organized as follows: the literature review is provided in Section 2. Section 3 discusses the theoretical background of this study. The research model and hypotheses are presented in Section 4. The empirical study is described in Section 5. This is followed by a discussion of the findings and limitations of this study in Section 6. Section 7 concludes this research and suggests directions for future research.

\section{Literature review}

The literature about technology adoption and mobile services adoption is discussed in this section.

\subsection{Technology adoption}

An important and long-standing research question in information systems research is how to accurately explain user adoption of information systems [21]. Several models have been developed to test the users' attitude and intention to adopt new technologies or information systems. These models include the Technology Acceptance Model (TAM) [19], Theory of Planned Behavior (TPB) [2], Innovation Diffusion Theory (IDT) [60], Unified Theory of Acceptance and Use of Technology (UTAUT) [69]. Among the different models that have been proposed, TAM, which is an extension of the Theory of Reasoned Action (TRA) [24], appears to be the most widely adopted model. TAM focuses on the perceived usefulness (PU) and perceived ease of use (PEOU) of a system and has been tested in some domains of E-business and proved to be quite reliable to predict user acceptance of some new information technologies, such as intranet [37], World Wide Web [44], electronic commerce [57], and online shopping [28].

In contrast to TPB and IDT, TAM has substantial theoretical and empirical support, and it is well known for its parsimony. TAM has proven to be a parsimonious model with high explanatory power 
of the variance in users' behavioral intention related to IT adoption and usage across a wide variety of contexts [64]. TAM explains and predicts user intention and usage using two main constructs, perceived usefulness and perceived ease of use. These two factors are easy to understand and to test in practice. Hong et al. [36] argue that the flexibility of TAM makes it suitable for various diverse technologies. TAM can be conceived as a fundamental model to study the adoption of mobile services.

However, TAM's limitations relative to extensibility and explanation power have been noted [9]. Many researchers have suggested that TAM needs to be extended with additional variables to provide a stronger model [46]. Some argued that the constructs of TAM do not provide sufficient implications to practitioners [10]. Further, others mentioned that TAM is too generic to provide a realistic understanding with regard to the adoption of advanced mobile services and technologies [12]. Therefore, PU and PEOU may not fully explain people's intention to adopt mobile services. We believe that TAM has limitations when investigating user adoption of mobile services, which is also confirmed by prior research [71].

Although UTAUT includes more constructs into the model, it has its own limitations. In [6], Bagozzi criticize UTAUT for its lack of parsimony. Since UTAUT unifies more factors and consolidates the functions of the technology acceptance model with the constructs of other prominent models in IS adoption research, it increases the complexity and it is more complicated to test its applicability.

As the context in which consumers use mobile services may be more influential than the mobile services, PU and PEOU may not be adequate to cover all the factors which can explain users' adoption of mobile services. Therefore, we believe it might be helpful to integrate some factors with TAM to study the adoption of mobile services, which can in turn deepen our understanding of factors that contribute to the diffusion of mobile services. This research is based on TAM. Three additional factors, Trust, Context, and Personal Initiative and Characteristics, are added to TAM to examine students' perception of mobile information services at a Norwegian university. The inclusion of these three factors is based on theoretical background which is presented in the next section.

\subsection{Mobile services adoption}

Compared to the rapid development of mobile technology, the research on mobile services adoption, particularly on newly developed advanced mobile information services, is still in the infancy stage. According to Hosbond et al. review on the literature on mobile system development [38], the previous research tends to have a strong focus on the technology perspective, which focuses on how the related technologies contribute to the development of mobile systems. There are only a small number of studies focusing on mobile services adoption.

Some studies based on TAM and the other theories presented above have explored factors affecting consumer adoption of mobile services. Some of these studies are summarized in Table 1. For instance, $\mathrm{Lu}$ et al. [48] studied the acceptance of wireless Internet via mobile technology (WIMT) in China and indicated that the acceptance of WIMT is related to perceived usefulness, ease of use, social influence, trust, and facilitating conditions. Luarn et al. [49] extended the applicability of TAM to the context of mobile banking, by adding perceived credibility, perceived self-efficacy and perceived financial cost to the model. Their findings strongly support the extended TAM in predicting users' intentions to adopt mobile banking. Yang [73] extended TAM to study factors affecting Singaporeans' attitudes toward mobile commerce. Evidence to support the extended TAM was found in this study. By expanding TAM and IDT, Chen [15] proposed a research model that examined the factors which determine consumer acceptance of mobile payment. Significant support for the model was found in the data collected from a survey of 299 potential mobile payment users. 
Table 1

Literature review on mobile services adoption

\begin{tabular}{|c|c|c|c|}
\hline Literature & Research purpose & Theory used & Findings \\
\hline Chen [15] & $\begin{array}{l}\text { Explore the issues of con- } \\
\text { sumer acceptance of } \mathrm{m}- \\
\text { payment. }\end{array}$ & TAM and IDT & $\begin{array}{l}\text { The findings show that consumer accep- } \\
\text { tance of m-payment were determined by } \\
\text { four factors: Perceived usefulness (PU), per- } \\
\text { ceived ease of use (PEOU), perceived risk } \\
\text { (PR) and compatibility. }\end{array}$ \\
\hline Lu et al. [48] & $\begin{array}{l}\text { Develop the technology } \\
\text { acceptance model for wire- } \\
\text { less internet via mobile } \\
\text { devices (WIMD). }\end{array}$ & $\begin{array}{l}\text { TAM and some additional } \\
\text { factors, such as technology } \\
\text { complexity, social influ- } \\
\text { ences, trust, etc. }\end{array}$ & $\begin{array}{l}\text { A framework for explaining factors that } \\
\text { influence individual acceptance of WIMD. }\end{array}$ \\
\hline Luarn et al. [49] & $\begin{array}{l}\text { Explore the factors deter- } \\
\text { mining users' acceptance } \\
\text { of mobile banking. }\end{array}$ & $\begin{array}{l}\text { Extend TAM with three ad- } \\
\text { ditional factors: Perceived } \\
\text { Credibility, perceived self- } \\
\text { efficacy, and perceived } \\
\text { financial cost. }\end{array}$ & $\begin{array}{l}\text { The findings strongly support the appro- } \\
\text { priateness of using this extended TAM to } \\
\text { understand the intentions of people towards } \\
\text { the use of mobile banking services. }\end{array}$ \\
\hline Hong and Tam [35] & $\begin{array}{l}\text { Study individual adoption } \\
\text { of mobile data services that } \\
\text { are used beyond conven- } \\
\text { tional work settings. }\end{array}$ & $\begin{array}{l}\text { General technology percep- } \\
\text { tions, technology-specific } \\
\text { perceptions, user psycho- } \\
\text { graphics, social influence, } \\
\text { and demographics. }\end{array}$ & $\begin{array}{l}\text { The findings show that the determinants of } \\
\text { the adoption of mobile data service are not } \\
\text { only different from those in the work place, } \\
\text { but are also dependent on the nature of the } \\
\text { target technology and its usage context. }\end{array}$ \\
\hline Nysveen et al. [55] & $\begin{array}{l}\text { Explore consumers' inten- } \\
\text { tion to use mobile services. }\end{array}$ & $\begin{array}{l}\text { Motivational influences, } \\
\text { Attitudinal influences, } \\
\text { Normative pressure, and } \\
\text { Perceived control. }\end{array}$ & $\begin{array}{l}\text { The empirical results show strong support } \\
\text { for the effects of motivational influences, at- } \\
\text { titudinal influences, normative pressure, and } \\
\text { perceived control on consumers' intentions } \\
\text { to use mobile services. }\end{array}$ \\
\hline Kuo et al. [43] & $\begin{array}{l}\text { Explore consumer's per- } \\
\text { ception of } 3 \mathrm{G} \text { mobile } \\
\text { value-added services, and } \\
\text { their behavioral intention } \\
\text { to use these services. }\end{array}$ & $\begin{array}{l}\text { TAM, Personal Innovative- } \\
\text { ness, Perceived Cost. }\end{array}$ & $\begin{array}{l}\text { Consumer usage rate of current } 3 \mathrm{G} \text { value- } \\
\text { added services remains low. Consumers } \\
\text { with higher personal innovativeness per- } \\
\text { ceive a higher ease of use of value-added } \\
\text { services. }\end{array}$ \\
\hline Mao et al. [51] & $\begin{array}{l}\text { Explore key factors that } \\
\text { influence the usefulness, } \\
\text { ease of use, and intentions } \\
\text { to use mobile services, } \\
\text { such as Email, payment. }\end{array}$ & $\begin{array}{l}\text { TAM, Price, Accessibil- } \\
\text { ity, Efficacy, and Personal } \\
\text { Innovativeness. }\end{array}$ & $\begin{array}{l}\text { The findings provide support for the tech- } \\
\text { nology acceptance model across both } \\
\text { groups and for the importance of variables } \\
\text { such as efficacy and personal innovative- } \\
\text { ness. }\end{array}$ \\
\hline Yang et al. [73] & $\begin{array}{l}\text { Explore factors affecting } \\
\text { the adoption of mobile } \\
\text { commerce in Singapore. }\end{array}$ & $\begin{array}{l}\text { TAM, Past adoption behav- } \\
\text { ior, Demographic variables. }\end{array}$ & $\begin{array}{l}\text { The findings show that TAM was capable } \\
\text { of providing an adequate explanation of } \\
\text { consumer adoption decision making process } \\
\text { to use the M-commerce. }\end{array}$ \\
\hline Chang and Pan [14] & $\begin{array}{l}\text { Explore factors affecting } \\
\text { the adoption of multimedia } \\
\text { messaging service (MMS). }\end{array}$ & TAM & $\begin{array}{l}\text { The findings show that relative advantage } \\
\text { and ease of use are important factors signifi- } \\
\text { cantly influencing mobile users' adoption of } \\
\text { MMS. }\end{array}$ \\
\hline
\end{tabular}

This research aims to complement and extend existing research by focusing on students' adoption of mobile student information services. The research also enables us to investigate the suitability of the mobile services acceptance model for predicting students' adoption behavior with a newly developed mobile information service at a university campus setting.

Interaction between students and instructors is very important in a university setting. Compared with a traditional university campus setting that mainly use desktops or laptops for interaction, some students have started using mobile devices in some studying related activities. In this study, we want to examine 
the issue of adopting mobile information services at a university. Based on our literature review and the summarized literature on mobile services adoption in Table 1, we found that the number of studies using individual consumer samples to investigate people's intention to use newly developed advanced mobile services is small. Most previous mobile services diffusion studies focus on general mobile services like voice, data services, and messaging. Although some studies have been done on mobile services adoption, we have not found any study on the adoption of mobile information services in a university campus setting. In addition, the students in this study were not forced to try the mobile service out. The participants used the service at their own free choice. We believe that studying the adoption of mobile information services at a university is important as it provides insights to develop mobile information services that are better suited for studying related activities.

This research is a continuing effort in studying the potential factors affecting mobile services acceptance. The next section elaborates on the factors to be included in our research model.

\section{Theoretical foundation}

While the acceptance and adoption of IT services has been one of the most prevailing IS research topics (e.g., [20,64]), the pervasiveness of mobile services raises new questions in exploring the adoption of mobiles services, such as what are the key factors driving the adoption of mobile services, and how do usage context affect users' adoption of mobile services. In this section, we provide the theoretical foundation for some factors to be included into the research model which is presented in the next section.

\subsection{Role of context in mobile services}

The term context has been extensively used in research related to mobile technologies. A unique feature of mobile services is its ability to be applied in different contexts. A context often describes the surrounding circumstances of mobile services and context has important implications in mobile computing.

Context provides an understanding of the way and circumstances for performing an activity [8]. Mobile services are often developed to provide an alternative channel for accessing services, not to replace the existing channels completely. When a service needs to be accessed immediately regardless of time and place, the perceived usefulness of the mobile service should be high and that would implicitly influence users' intention to use the service. Because a user's concerns and needs vary with the context in which s/he uses a service, services that can meet the user's needs in a specific context will provide the best value to the user [23]. Therefore, we believe that context plays an important role in the adoption of mobile services.

Based on the context, a user can decide whether mobile services are useful or not. For example, if people have no access to a desktop computer, they will perceive accessing information systems via mobile devices as useful. Prior research [3] found that there were significant differences between experienced users and inexperienced users in the influence on intention to use. In [63], the authors also indicated that, for experienced users, there was a stronger intention to use the technology/service. We believe that users' perception of the ease of use and usefulness of mobile services may vary in different contexts.

\subsection{Role of trust in mobile services}

Trust is a crucial enabling factor in relations where there is uncertainty, interdependence, risk, and fear of opportunism [52]. For example, because of the absence of proven guarantees that the mobile services 
providers will not engage in harmful opportunistic behaviors, such as privacy violations and unauthorized use of credit card information, some users generally stay away from mobile services providers they do not trust.

In the domain of mobile services, trust can be defined as a user's belief or faith in the degree to which a specific service can be regarded to have no security and privacy threats [26]. In other words, trust means believing in mobile services now with an expectation that it will be risk free and you will be getting intangible benefits in certain ways at an unspecific time in the future. For mobile services providers, cultivating users' trust is a time-consuming process. Trust is hard to gain, but easy to lose.

Several factors can influence users' trust in mobile services. First, many users are not familiar with mobile services and mobile technology. Second, unfamiliarity with mobile services providers may make users perceive the activities involved in mobile services as risky. For example, the lack of physical presentation of the service providers and the inability to feel and inspect the desired real products in a mobile transaction may make users feel vulnerable. Third, mobile services are also confronted with other challenges (e.g., privacy and security issues). Most users are concerned about the security of mobile services and mobile services providers' ability to protect unauthorized access to personal information. As indicated in [34], security and privacy issues are critical to the success of consumer trust building in Internet shopping. We believe that this principle can apply to mobile services as well. Compared to traditional electronic services, users tend to perceive mobile services as riskier in nature and are more hesitant to adopt them. Fourth, corporate branding and reputation could be used to engender trust in mobile services. Last but not least, legislations and governmental policies on mobile shopping may also affect users' trust.

In [62], the authors developed a trust building framework. In this framework, two main factors influencing trust in mobile commerce were suggested: trust in mobile technology and trust in mobile vendors. Trust in technology is dependent upon one's knowledge and experience of the technology. Trust in vendor primarily depends on the one's perception of the vendor. Building one's trust in a vendor is more challenging than gaining one's trust in technology. The authors [62] also indicated that building customer trust in mobile commerce is a continuous process, which extends from initial trust formation to continuous trust development, and with mobile technology and vendors as essential framework elements.

\subsection{Role of personal initiatives and characteristics in mobile services}

Personal initiatives and characteristics as key factors of technology diffusion are increasingly being recognized in academic and practitioner communities. Personal initiatives and characteristics cover many possible constructs, including past experience with specific technology, personal innovativeness [1], perceived enjoyment [33], personal willingness, social image, economic status, etc.

As one aspect of personal initiatives and characteristics, perceived enjoyment [33] can be defined as the extent to which fun can be derived from using the systems as such. In [55], Nysveen et al. revealed that perceived enjoyment stands out as an important motive for using experimental mobile services. In [31], the importance of enjoyment in a mobile augmented reality application for presenting cultural heritage information is highlighted. Many mobile services are not only aiming to offer convenience for work related activities, but also to provide fun for users.

Innovativeness is defined as the extent to which an individual is early in adopting new ideas relative to other members of a society [60]. As indicated in [1], individuals with higher level of innovativeness with respect to information technology have higher intentions toward the use of new information technology. These users can be regarded as active information seekers. They are able to deal with high level of 


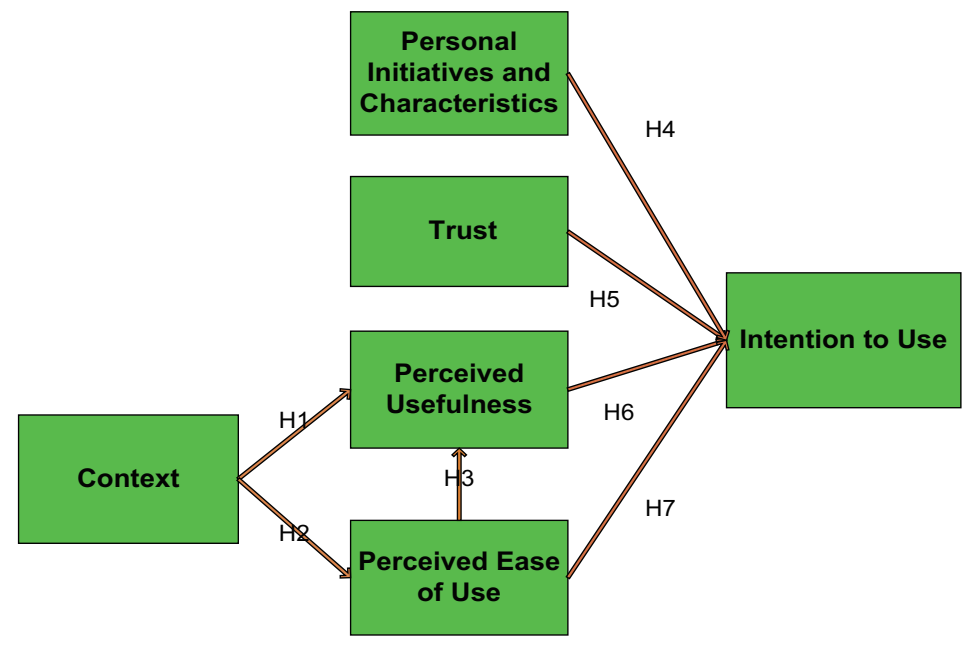

Fig. 1. Mobile services acceptance model.

uncertainty, and develop more positive intentions toward adoption [60]. Considering that mobile services can be seen as technological innovations, it is appropriate to include personal innovativeness as one variable in personal initiative and characteristics to test users' intention to adopt mobile services.

User willingness and needs also play an important role in the adoption of mobile services. Some organizations may encourage their employees to use new information technology by offering rewards. It should be noted that mobile services are mainly designed for individual users, who may have different expectations and needs according to their preferences. Because different users might perceive a mobile service in different ways, their intention to use a mobile service might differ.

Equipment costs, access costs, and transaction costs are three important components [17] that make using many mobile services more expensive than using wired electronic services. The impact of potential additional costs has not received much attention in previous IS adoption research because most prior studies focused on user behavior in an organizational setting, where users did not pay for new services or technologies. Concerning mobile services, young individuals may have great interest in experiencing new services and technologies. However, they may not be able to afford the additional costs associated with the new services and technologies because of their low income.

In some countries, social image is critical for many people. When penetration of advanced mobile services via mobile devices is not substantial, users may regard these devices as symbols of fashion and wealth, and adopt these devices to enhance their sense of self-importance [61].

\section{Research model and hypotheses}

A research model that identifies important major factors as significant antecedents of users' intention to use mobile services was developed in [26]. The proposed mobile services acceptance model (see Fig. 1) is an extension of TAM. In addition to perceived ease of use and perceived usefulness, the model includes trust, context, and personal initiatives and characteristics as factors to study the relating to user adoption of mobile services. The research model was constructed based on the theoretical and conceptual background described in the last Section.

Table 2 summarizes the definition of the constructs in the mobile services acceptance model. 
Table 2

The definitions of the constructs

\begin{tabular}{|c|c|c|}
\hline Construct & Definition & Reference \\
\hline Context & $\begin{array}{l}\text { Any information that can be used to characterize the situation of entities that are } \\
\text { considered relevant to the interaction between a user and an application, including } \\
\text { the user and the application themselves. }\end{array}$ & [22] \\
\hline $\begin{array}{l}\text { Personal initiatives } \\
\text { and characteristics }\end{array}$ & The user's willingness to experiment with new services. & [26] \\
\hline Trust & $\begin{array}{l}\text { The user's belief or faith in that a specific service can be regarded to have no security } \\
\text { and privacy threats. }\end{array}$ & [26] \\
\hline Perceived ease of use & $\begin{array}{l}\text { The extent to which a person believes that using a particular system would be free of } \\
\text { effort. }\end{array}$ & [19] \\
\hline Perceived usefulness & $\begin{array}{l}\text { The degree to which a person believes that using a particular system would enhance } \\
\text { his or her task. }\end{array}$ & [19] \\
\hline Intention to use & The user's likelihood to engage the mobile service. & {$[19,24]$} \\
\hline
\end{tabular}

\subsection{Research hypotheses}

We have developed seven research hypotheses based on the research model. Each hypothesis as labeled in Fig. 1 is elaborated below.

\subsubsection{Context}

A unique attribute of mobile services is that it can be used in a variety of contexts, which can deliver some services that traditional E-business could not provide. Users' perception on mobile services varies in different contexts. In [25], the authors argued the importance of context towards mobile services adoptions. With various contexts, a mobile service will be perceived differently with regard to ease of use and usefulness. Users see more potential to use mobile services on mobile devices in an ever changing environment or an emergent situation. Thus, they should perceive a mobile service as more useful in this context. This is in line with the research findings [74] that enabling mobile devices and services to adapt to the changing environment will enhance user experience. Mallat et al. [50] found that the use situation of the mobile ticketing services has a significant effect on users' intention to use such services. In [45], the author proposed a new concept contextual perceived usefulness by combining context and perceived usefulness to investigate mobile commerce acceptance. In our research, we investigate to what extent context affects perceived usefulness and perceived ease of use directly. Thus, we propose the following hypotheses:

H1. The appropriate context has a direct positive effect on Perceived Usefulness of mobile services.

H2. The appropriate context has a direct positive effect on Perceived Ease of Use of mobile services.

\subsubsection{Personal initiatives and characteristics}

Prior research suggests that personal innovativeness is an important indicator for user acceptance of IT/IS $[1,18,47]$. By extending the concept of personal innovativeness, we proposed a new construct, named personal initiatives and characteristics, aiming to better address the effects of individual difference toward user acceptance of mobile services.

With regard to adoption of mobile services, many people may not want to take the initiative in trying advanced mobile services since they do not have any knowledge or experience with such services. Personal initiative is also closely associated with individual characteristics. Individual characteristics, such as curiosity and perceived enjoyment, may strongly enhance users' perception of mobile services 
and lead to positive attitudes toward mobile services. Generally, people with strong positive personal initiatives and characteristics are more likely to try new technologies, thus it is reasonable to expect them to have positive intentions to use mobile services. Moreover, people's attitudes toward innovations have been used to predict the adoption of mobile commerce [73]. Therefore, it is believed that personal initiatives and characteristics may well serve as a key determinant for acceptance decision of mobile services and have the potential to directly affect intention of use. Based on this, we posit the following hypothesis:

H4. Personal Initiatives and Characteristics have a direct positive effect on Intention to Use of mobile services.

\subsubsection{Trust}

Users may feel threatened when the technology has the capability to track users' actions and store personal information outside the users' control. Several factors can lead to unauthorized access of users' personal information: hacking, security defects, accidental disclosure, etc. A potential adopter usually wants to maximize benefits and minimize risks. On one hand, in order to provide personalized services, mobile services provider may need to locate users' position and collect users' profiles. On the other hand, users would like to obtain desired mobile services by disclosing minimum personal information. Therefore, we believe trust is an important issue relative to mobile services adoption. In other words, trust is a significant antecedent of participation in the activities involved in mobile services. Trust can help reduce the uncertainties a user faces when using mobile services.

In [29], the authors extended TAM with trust in the service provider to study user acceptance of online shopping. They found that trust-related issues have a considerable effect on user acceptance of online shopping. Since context-aware mobile services often need to collect information about the user, it is crucial for users to pay more attention to trust related issues, such as privacy, security, etc. Building users' trust is also a continuous process. As users get used to mobile services, the reliability of mobile services become more important to accumulate users' trust or believability in such services. Consequently, to better explain the importance of trust towards mobile services adoption, we propose the following hypothesis:

H5. Trust has a direct positive effect on Intention to Use mobile services.

\subsubsection{Perceived usefulness (PU)}

Perceived usefulness originally refers to job-related productivity, performance, and effectiveness [19]. A number of researchers have examined the TAM model for various information systems and technologies, including the World Wide Web (WWW) [40], Intranet [37], wireless internet [48], desktop video conferencing in virtual workgroups [66], etc. In those studies, PU was found to have a strong effect on technology adoption. The empirical findings in those studies demonstrate the importance of PU on intention to use the technologies. Assuming that the TAM model is viable for explaining adoption perception, we thus hypothesize:

H6. Perceived usefulness has a direct positive impact on intention to use mobile services.

\subsubsection{Perceived ease of use (PEOU)}

Borrowed from TAM, perceived ease of use refers to "the degree to which the prospective user expects the target system to be free of effort". This belief is associated with an individual's assessment of the mental effort involved in using a system. PEOU reflects how difficult it will be to use a new technology 
or system. Venkatesh [68] stated that for any emerging IT/IS, perceived ease of use is an important determinant of users' intention of acceptance and usage behavior. According to a survey [16] done by Embedded Solutions among 800 professionals in England, perceived ease of use is among the top five factors for determining the use of wireless handheld devices. This finding was also confirmed by other studies on mobile data services and mobile commerce $[47,75]$.

Further, in the original TAM model, Davis [19] proposed that perceived ease of use affects perceived usefulness. There is extensive empirical evidence that perceived ease of use positively influences perceived usefulness [46]. In [32], the author also found that this relationship holds true for website usage in an internet environment.

Mobile services are provided on mobile devices such as smart phones and PDAs. The limitations of mobile devices may have the potential to affect users' perceptions of ease of use of mobile services. The limitations include small keyboard, small screen, inadequate battery capacity, slow network connections, slow CPU speed. Improved ease of use of mobile services by taking these limitations into consideration would have positive impacts on both perceived usefulness and users' acceptance of mobile services.

To keep in line with the existing literature in mobile services diffusion, we thus hypothesize:

H3. Perceived Ease of Use of mobile services has a direct positive effect on Perceived Usefulness of mobile services.

H7. Perceived Ease of Use has a direct positive impact on intention to use mobile services.

\section{An empirical study on the acceptance of eMSIS}

In this empirical test, the mobile services acceptance model was examined through the use of a mobile service called extended mobile student information systems (eMSIS), by university students on the university campus. The database of eMSIS is connected with the official student information registration system at the university. Students need to login with their usernames at the university to access relevant study-related information such as information on their courses. eMSIS can make use of contextual information such as location (based on a WLAN-based indoor positioning system), time, and personal preferences to provide the user with relevant and timely information, which is more or less similar to some mobile services in the commercial market. For example, the 'location finder' function of eMSIS allows users to search for different "points of interest" throughout campus (lecture rooms, computer labs, canteens, etc.). This part of the system has lately been made generally available, with 15000 downloads so far [42]. Therefore, this mobile service is a good case for instrument testing and identifying relevant implications for practitioners.

\subsection{Mobile information services: eMSIS}

eMSIS [5] is an extended system built upon MSIS [53] which was developed at Norwegian University of Science and Technology as part of the activities within the Wireless Trondheim Living Lab [4]. The main purpose of eMSIS is to offer a number of mobile services that can assist students in their daily study-related activities on the university campus.

Some main functions provided by eMSIS are:

- Twitter: Allow students to follow courses updates, student activities and fellow students in a university setting. Users can share and discover what's happening with studying-related matters through the Twitter Service of eMSIS. 
Table 3

Demographic information of the subjects

\begin{tabular}{lrr}
\hline & Number & Percent \\
\hline Gender & 36 & 78.3 \\
$\quad$ Male & 10 & 21.7 \\
Female & & \\
Age & 1 & 2.1 \\
$\quad$ Less than 20 & 36 & 78.3 \\
20-29 & 9 & 19.6 \\
30 or over & & \\
Department & 39 & 84.8 \\
$\quad$ Science or engineering & 7 & 15.2 \\
$\quad$ Others & & \\
Educational level & 8 & 17.4 \\
$\quad$ Undergraduate students & 38 & 82.6 \\
$\quad$ Graduate students & & \\
Experience with mobile services & 11 & 23.9 \\
$\quad$ 0-1 year & 16 & 34.8 \\
2-5 years & 19 & 41.3 \\
$\quad$ More than 5 years & & \\
Geographical background & 18 & 39.1 \\
$\quad$ Norway & 6 & 13.1 \\
$\quad$ Africa & 22 & 47.8 \\
$\quad$ Asia
\end{tabular}
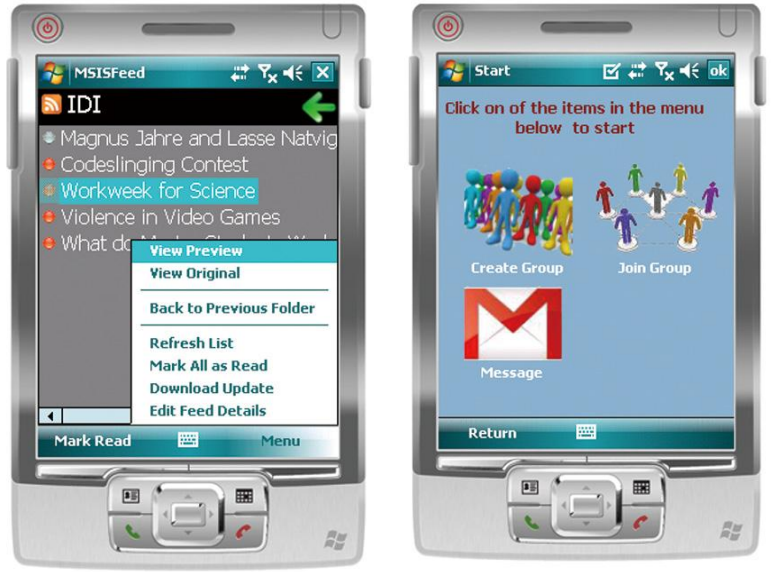

Fig. 2. The screenshots of eMSIS.

- Feeds: Allow students to be updated with university news and course announcements by subscribing feeds provided by the university and the course instructor.

- Project collaboration: Allow the students of a project/assignment to communicate with each other anytime anywhere.

- Location finder: Allow users to search for different type of locations on campus, e.g. lecture rooms, computer labs, canteens, etc. This is linked to the courses that the student is registered to take. It provides a short description of the location with an option to show the position of the location on a map. It can also position the user on the same map, and provide guidance for how to get to where you want to go.

- Lecture planner: Allow users to view scheduled lectures for a given day or week.

Figure 2 shows screenshots of the feeds service and the project collaboration service of eMSIS as they appear on a Windows Mobile 6 Professional emulator.

eMSIS is selected as the mobile information service in this experiment for three reasons: first, some testing scenarios (see Appendix 2 for four testing scenarios) have been prepared for individual testing, which is unlike most previous mobile services diffusion studies which focused on people's perceptions on general mobile services. Second, eMSIS is more or less similar to some other mobile information services on the commercial market. For example, the feeds function in eMSIS is similar to other feedsservices on the commercial market. Third, this study use students who are using technology by their own free will in a university campus setting, which is unlike some previous studies on technology diffusion, where the use is mandatory and in an organizational setting.

\subsection{Sample}

A lottery with two HTC Touch devices were included as incentive to attract students to participate in this experiment. We recruited the experiment subjects by posting announcements to a number of student 
mailing lists at a Norwegian university. Students from several departments, studying for an undergraduate program or a graduate program, were invited to participate in the experiment of using the eMSIS mobile service running on a HTC Touch Mobile device. Our postings explained who we were, what they are supposed to do during the eMSIS experiment, and the purpose of the experiment. The participants were also informed that the results would be reported only in aggregate and that their anonymity would be assured. We received responses from 46 students that confirmed to participate in the experiment. The demographic information of the respondents is summarized in Table 3. The subjects in this test were from different cultures and educational backgrounds. This diversity among the subjects was expected to produce a balanced result.

\subsection{Survey instrument}

The validated instrument measure in [27] was used as the foundation to create the instrument for this study. In order to ensure that the instrument better fit the specific mobile service experiment, some minor words changes were made to ensure easy interpretation and comprehension of the questions. In addition, we also included three additional items in this study based on suggestions from some fellow researchers in the technology diffusion community.

As a result, 25 measurement items (see Appendix 1) were included in the instrument survey. A sevenpoint Likert scale, with 1 being the negative end of the scale (strongly disagree) and 7 being the positive end of the scale (strongly agree), was used to examine participants' responses to all items in the survey.

\subsection{Data collection procedure}

A paper based survey questionnaire was created to enable rapid onsite distribution and collection during the experiment. Prior to completing the questionnaire, all participants were provided with an information sheet describing the mobile service - eMSIS and a mobile device having eMSIS installed. In this manner, all participants received some basic ideas about the mobile service. Then, they familiarized themselves with the mobile devices for around 15 minutes. eMSIS was designed to support students' daily activities on campus. Most participants had not used this kind of study-related mobile service on campus on mobile devices. Therefore, most participants mainly focused on using the device during this experiment. After using the eMSIS system in two of the four specified realistic scenarios (see Appendix 2) in the university campus environment for 45 minutes, the questionnaire was distributed to all participants. The first scenario uses the twitter service. The second scenario uses the feeds service at the university. The third one uses course related documents downloading or uploading. The last scenario is using project collaboration service in a specific project based course. After filling out the questionnaire, the participants returned the completed survey to us.

\subsection{Descriptive results}

Some key findings from the descriptive results are summarized here (see Appendix 3 for the means and standard deviations for each of the items in the survey).

The mean value for the measurement item (PU4) was 5.52. 38 respondents agreed that the eMSIS system would be useful for them as students, while six respondents did not know if it would be useful and two respondents somewhat disagreed that the eMSIS system would be useful. Although most participants knew about Twitter and feeds services, they might not have a clear conception about how these services can be related to studying activities. 
According to the results, most respondents thought that they would not have any problems with learning to use the eMSIS system (EU1). 21 of the 46 respondents (45.7\%) strongly agreed that it would be easy for them to learn how to operate the eMSIS system. According to our observation on participants' behavior during the experiment, we found that most Norwegian students were able to finish the assigned tasks quite quickly without asking any help from the instructors. Some students from Asia and Africa asked for some help from the instructors, because they had less experience with using mobile services.

The most important factor in the trust construct is related to privacy issues (TU3). The second most important factor with regard to trust is the reliability of the data provided by the system. Since the retrieved data is essential for the students to keep updated about studying related information, it is understandable that most students rated their belief in the item TU5 high (feel confident that the data returned by the system is reliable). The least important item in the construct Trust is the system provider and service provider (TU2). This can be partially attributed to that most students thought that the reputation of the system provider (regarded to be the university) is good. This may have turned out differently if the mobile service is related to some financial services, such as mobile payment, for which the service providers' reputation is likely to be of greater concern.

Item PIC4 has the highest mean value in the construct Personal Initiatives and Characteristics. Most respondents indicated that they found it rewarding to use the eMSIS system (PIC4). Furthermore, many of respondents thought that the eMSIS system was somewhat interesting to use (PIC1). Students were least concerned about the measurement item "using the eMSIS can be considered as a social status symbol among friends" (PIC5). But it is still worth to notice that some respondents from Asia and Africa strongly agreed with this statement. The mean value for this item may turn out differently if the mobile service is tested in Asia or Africa. In many Asian countries, young people often treat using smart phones and mobile services as a new fashion show-off. Having high-end smart phones can also be considered as a symbol of high social status.

As expected, the descriptive results indicated that students are likely to use the system if they are in a situation where they do not have access to a desktop computer or a laptop. Another observation was that many participants would also be likely to use the service if it would be meaningful to the students' daily tasks. It is also interesting to note that 39 respondents agreed that they did need encouragement from the university to use eMSIS.

\subsection{Data analysis}

To test the reliability and validity of each construct in the mobile service acceptance model, the Internal Consistency of Reliability (ICR) of each construct was tested with Cronbach's Alpha coefficient.

For the purposes of testing the research hypotheses, partial least squares (PLS) analysis was used. PLS is a regression-based technique, with roots in path analysis $[58,70]$. It has emerged as a powerful approach to studying causal models involving multiple constructs with multiple measures [65]. PLS allows people to do a combined regression and principal components factor analysis within the same statistical technique. In this study, the collected data was analyzed using the statistical software Smart PLS 2.0 and SPSS Version 17.

The fitness of the hypothesised model can be assessed using six commonly used fit indices [39]: Chi-square, Chi-square/df, Normed Fit Index (NFI), Comparative Fit Index (CFI), Root Mean Square Residual (RMR) and Root Mean Square Error of Approximation (RMSEA). While the Chi-square statistic is a global test of a model's ability to reproduce the sample variance/covariance matrix, it is highly sensitive to sample size and model complexity. Therefore, other model-fit indices such as CFI that are 
Table 4

Reliability analysis of constructs

\begin{tabular}{lcc}
\hline Constructs & $\begin{array}{c}\text { Number } \\
\text { of items }\end{array}$ & $\begin{array}{c}\text { Cronbach's } \\
\text { alpha }\end{array}$ \\
\hline Context & 4 & 0.732 \\
Intention to use & 2 & 0.916 \\
Perceived ease of use & 4 & 0.805 \\
Perceived usefulness & 4 & 0.827 \\
Personal initiatives and characteristics & 5 & 0.842 \\
Trust & 6 & 0.650 \\
\hline
\end{tabular}

independent of sample size should be evaluated along with the Chi-square statistic. CFI was the primary fit-statistic of the six for the purposes of this study, as recommended by [11]. A CFI above 0.90 is indicative of a well-fitting model. According to our result, CFI is above 0.90 in this study. This means that the resulting measurement model has good model-to-data fit.

\subsection{Test of measure}

The Internal Consistency of Reliability (ICR) of the measurement model was accessed by computing Cronbach's Alpha coefficient. Table 4 displays the reliability coefficients for each of the constructs in our measurement model.

The Cronbach's Alpha values range from 0.652 to 0.916 . All the constructs but the construct Trust is above 0.700 . The lower reliability for the construct Trust can be partly attributed to the large number of measurement items in the scale. According to previous research work [59], a reliability coefficient of 0.6 is marked as a lowest acceptable limit for Cronbach's Alpha for exploratory research. Moss [54] also suggested that an alpha score of 0.6 is generally acceptable. All Cronbach's Alpha values of the constructs in our model are above threshold 0.6. Consequently, the scales were deemed acceptable to continue.

\subsection{Structural measurement model}

Figure 3 presents the structural measurement model using the PLS algorithm. The number in the circles in Fig. 3 means R2 (R square), which denotes to coefficient of determination. R2 provides a measure of how well future outcomes are likely to be predicted by the model, the amount of variability of a given construct [56]. In our PLS analysis, the R2 coefficient of determination is a statistical measure of how well the regression coefficients approximates the real data point. The amount of variance in Intention to Use explained by the model was 0.663 . The explained variance of Perceived Usefulness factor is $32.5 \%$. The percentage of variance explained for Perceived Ease of Use is 21.4.

Table 5 shows the path coefficients, which are standardized regression coefficients, generated from the PLS analysis. As such, the seven hypotheses were supported. In addition, all the seven hypotheses were statistically significant $(p<0.05$ or $p<0.01)$.

\section{Discussions}

The findings of this empirical study provide some insights to both researchers and practitioners. On one hand, from an academic perspective, this study contributes to the literature on mobile services adoption and diffusion by identifying and validating the potential factors affecting the adoption of mobile 
Table 5

Test of hypotheses based on path coefficient

\begin{tabular}{lccc}
\hline Hypothesis & $\begin{array}{c}\text { Path } \\
\text { coefficient }\end{array}$ & $\begin{array}{c}T \text { value } \\
\text { Hypothesis } \\
\text { result }\end{array}$ \\
\hline H1. Context to perceived usefulness & $0.152^{* *}$ & 8.335 & $\begin{array}{c}\text { Supported } \\
\text { H2. Context to perceived ease of use }\end{array}$ \\
H3. Perceived ease of use to perceived usefulness & $0.463^{* *}$ & 7.828 & Supported \\
H4. Personal initiatives and characteristics to intention to use & $0.484^{* *}$ & 5.623 & Supported \\
H5. Trust to intention to use & $0.166^{* *}$ & 3.927 & Supported \\
H6. Perceived usefulness to intention to use & $0.216^{*}$ & 2.1007 & Supported \\
H7. Perceived ease of use to intention to use & $0.326^{* *}$ & 6.850 & Supported \\
\hline
\end{tabular}

$* p<0.05 ; * * p<0.01$.

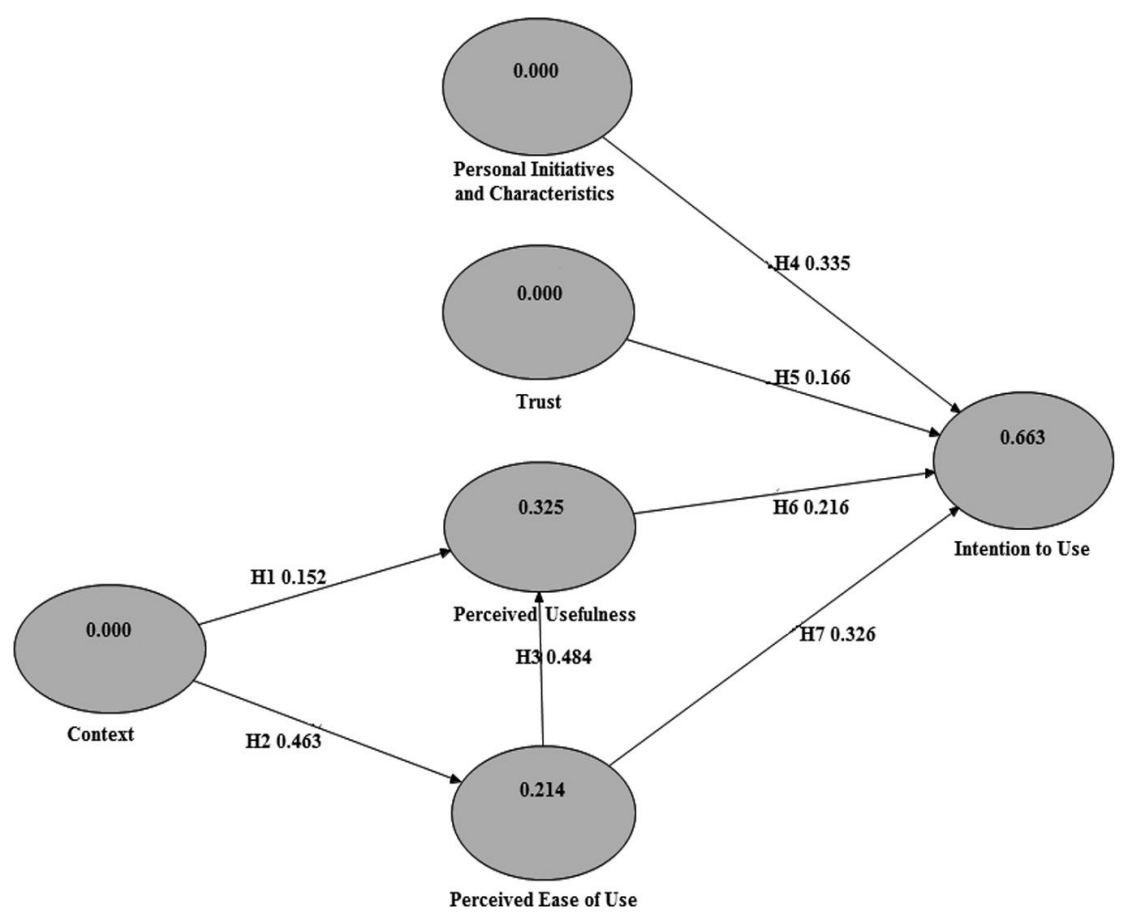

Fig. 3. The structural model.

information services. The findings demonstrated the appropriateness of the research model and hypotheses for measuring mobile services adoption. On the other hand, from a business perspective, the statistic results of the research model also provided some insights for practitioners to better design and develop mobile services with higher user acceptance.

With regard to the mobile information service used in our test, most previous empirical studies on mobile services adoption and diffusion focus on simple mobile services, such as mobile instant messaging, voice communication, and mobile web browsing. What sets us apart from previous studies is that we empirically tested our research model and hypotheses in a relatively advanced mobile information service with the possibility to provide personalized services and location-based services, which were supposed to provide some new implications for mobile service providers and developers to develop better mobile services to attract more users to adopt the services.

Most research models in the previous adoption studies as summarized in Table 1 were empirically 
tested using data from online survey. In our study, to better understand students' reaction to eMSIS, we observed students' reaction to eMSIS during the on-campus experiment. Some interesting findings were described in the descriptive results part in the last section. In addition, we found that, in general, foreign students from Asia and Africa at the Norwegian university were less comfortable with eMSIS than students from Norway at the Norwegian university. Compared to traditional information services on desktops or laptops, information services on mobile devices provide consumers a great degree of convenience. However, mobile services are still in the early stages of diffusion in most regions of Asia and Africa. The students from Asia and Africa were more uncomfortable and unfamiliar with mobile services. During the experiments, some students from Asia and Africa were having problems in using eMSIS and needed guidance from the instructors. For a few students, the experiment was the first time they encountered mobile services on high-end mobile devices. The implication of this is that mobile services' vendors and providers need to create more convenient mobile services to help customers accustomed to and be comfortable with using mobile services.

The result showed that the most important determinant for intention to use is Personal Initiatives and Characteristics. This is consistent with findings in the previous mobile adoption studies presented in Table 1 (e.g., [43,51]). Since most subjects in this study have certain level of mobile computing knowledge and experience with mobile services as shown in the statistics in Table 3, it seems easy for them to obtain the willingness to adopt newly developed mobile services. And this construct played a more important role than perceived usefulness in predicting students' adoption of eMSIS. The possible reasons are as follows. A number of advantages in using mobile services (such as convenience, fun, etc.) might entice users to adopt them even though some functions in the mobile service are perceived not to be very useful. For instance, during the course of the experiment, some participants expressed excitement and joy while using the eMSIS system. They might conceive that the entertainment factor, which is one of candidate items in the construct Personal Initiatives and Characteristics, was more important than actual usefulness of the system, although the system is primarily though to be utilitarian. It is found that user experience literature often includes non-instrumental values such entertainment as well [30]. For example, [67] showed the choice of personalised user interfaces ('skins') to be driven by aesthetic and symbolic considerations. However, this does not mean that the eMSIS system is not useful. It is merely an indication that the perceived usefulness might not be a determining factor to the intention to use for the respondents in this test. This is also in line with the ideas behind our research model that some other factors in addition to perceived usefulness and perceived ease of use may strongly affect users' adoption of mobile services.

Another interesting finding is the weak impact of Perceived Usefulness on adoption. This contrasts with most previous findings on adoption of mobile services for work settings. One plausible explanation is that the study was conducted on campus with students using eMSIS. Students had relatively easy accessed to other computing devices to access student information systems on campus. As such, this might affect the students' answers to the questions regarding Perceived Usefulness in the survey.

Our study is one of the first that includes the trust construct in mobile information services adoption. The results indicated that the trust construct has a positively direct effect on intention to use. This demonstrated that trust is one of the factors to positively influence customer's intention to use mobile services. The higher the user trusts the system and the provider of the system, the higher the intention to use will be. In [48], the authors hypothesized that wireless trust environment would have a significant effect on perceived usefulness of mobile services. However, they did not empirically test their hypotheses. In our study, we empirically demonstrated that trust is a very important determinant of mobile information services adoption. Further studies on the impact of trust will be needed in other advanced mobile services. 
It was also found that the relevant context positively affects perceived usefulness and perceived ease of use directly. This finding was in accordance with the results of [72], which pointed out that context has a significant effect on both perceived usefulness and perceived ease of use.

This study also has some practical implications. The results of this empirical test can provide guidelines and suggestions to mobile services providers and developers in offering appropriate services to users in various contexts. The findings suggest that users need the right mobile service in the right context at the right time. For example, most participants stated that they are likely to use the mobile service if they do not have access to laptops and the service is highly associated with their study related tasks. Mobile services providers and developers should try their best to design services to address users' expectation on perceived usefulness and perceived ease of use. Mobile services providers and developers should improve their understanding of trust-related concerns and personal preferences and characteristics of the target users in order to fulfil the users' expectations. Being aware of the proposed factors affecting mobile services adoption in our research model would help the mobile service providers to set them apart from their competitors in developing mobile services.

Another practical contribution of this study is to help mobile information services vendors and providers identify groups of consumers who have a strong intention to adopt newly developed mobile services. Our study demonstrates that some additional factors need to be considered to serve target mobile services consumers in various settings.

Instructors who are interested in using mobile services for academic related activities should be aware that students are likely to use mobile services to enhance interaction with instructors when they are not in the physical classrooms at a university. From the on-site observation during the experiment, although some students from Asia and Africa were not familiar with using eMSIS on the high-end mobile devices, they expressed general interest in information that was provided by eMSIS. From this study, we believe that mobile services similar to eMSIS will become more and more popular and be accepted by a larger number of students at various education institutions in the coming years.

Last but not least, our study also provides some implications for marketing personnel to promote their mobile information services in various regions all over the world. According to our findings, students from Asia and Africa are more likely to consider opinions of their fellows and their personal social image than Norwegian students when they are making a decision to adopt mobile service. During the experiment, some participants from Asia and Africa indicated that owning high-end mobile devices and using advanced mobile information services may be seen as a symbol of high social status. Therefore, marketing personnel may aim at promoting mobile information services to those users first in Asia and Africa.

However, we are also aware of some limitations of this work. Firstly, we only tested the research model and hypotheses on a single mobile information service. Therefore, the generalizability of the results to other mobile services remains to be determined. Secondly, eMSIS was introduced to the participant for the first time in this experiment. eMSIS was only tested in four designed scenarios on campus over a short time period. The behavior in a 45 minutes test might differ from usage and motives in real-life long-term use. We have not investigated the long term use of eMSIS on campus. In addition, the findings of this study may be limited due to the relatively small sample size. Last but not least, the subjects in this study were students. This sample may not be fully representative of the entire population. On the other hand, the service being tested was for students, thus they were actual prospective users, and not proxy-users. 


\section{Conclusion and future research}

This research was designed to study mobile information services adoption from university students' perspective. This study presents a pioneering effort in investigating the adoption of mobile information service at a university campus setting. To our knowledge, we have not found any study that focuses on understanding the adoption of advanced mobile information services, such as eMSIS, at a university. None of the previous studies as presented in Table 1 explored the adoption of such a mobile service. A research model based on technology acceptance models and seven research hypotheses were presented and empirically tested. From a survey with 46 users of eMSIS, we found that personal initiatives and characteristics, trust, perceived usefulness and perceived ease of use are key determinants on the adoption of eMSIS. Context via perceived usefulness and perceived ease of use has an indirect affect on intention to use. From our study, the findings revealed that personal initiatives and characteristics is the most important determinant of mobile information services adoption. The results indicate that the fitness of the research model is good and all the seven research hypotheses were supported.

We believe that this research makes an important contribution to the literature on mobile services adoption by adding some factors that influence the use of mobile services to TAM. Inclusion of these additional factors, such as trust and context, advances the knowledge on adoption of mobile services and helps to promote future research on mobile services diffusion.

Continuing with this stream of research, we plan to test mobile services acceptance model's validity in other empirical contexts, such as mobile banking and personalized news services. Future research is also needed to empirically verify the research model with larger samples in other universities.

As for the mobile service acceptance model, the generalizability of this model can be improved by expanding the study to include individuals representing different countries and cultures (e.g., some individuals from USA). Such a study can help researchers uncover country and culture (or ethnic) specific relationships.

A longitudinal study (i.e., a 6-month period) is another opportunity to re-validate the research model. By choosing a longitudinal method, the research can more closely examine the change in user behavior over time. Such a study can help to enhance the understanding of how and why students use eMSIS over time.

Also, we are aware that the life span of mobile services such as eMSIS can be short without an in-depth understanding of the potential consumers or markets. Once a service becomes popular, it may quickly lose its uniqueness and identity. Students may have a higher expectation on new mobile information services. For instance, some students would like to have a personalized mobile information service according to their personal preferences. Another possible future research requires another round of survey on the students' expectation on mobile information services at a university campus setting, which can help to further develop mobile services such as eMSIS to fulfil the students' needs.

\section{Appendix 1. Measurement items}

Perceived Usefulness (PU)

PU1. Using the system would increase the efficiency of my daily work.

PU2. The system would allow me to retrieve relevant events and news at NTNU.

PU3. The system would allow me to better plan and organize my activities at NTNU.

PU4. The system would be useful for me as a student. 
Perceived Ease of Use (PEOU)

PEOU1. Learning to operate the system would easy for me.

PEOU2. I would easily find the information I am looking for using the system.

PEOU3. I would find the system to be flexible to interact with.

PEOU4. I would find the system to easy to use (user-friendly).

Trust (TU)

I could use the system. . .

TU1. if I have a clear conception of the functionality of the system.

TU2. if the system provider(e.g. NTNU) and the software developers is widely acknowledged.

TU3. if the system protects the privacy of its users .

TU 4. if I feel confident that I can keep the system under control.

TU 5. if I feel confident that the data returned by the system is reliable.

TU 6. if I believe it is risk-free to use the system.

Personal Initiatives and Characteristics (PIC)

PIC1. I have fun using the system.

PIC2. I prefer to be the first one using the system.

PIC3. Using the system gives me an advantage over those who don't.

PIC4. I find it rewarding to use the system.

PIC5. Using this mobile system can be considered as a social status symbol among my friends.

Context (CT)

I could use the system...

CT1. if I am out of home or the office.

CT2. if the university encourage students to use the system.

CT3. if it is meaningful/relevant to my daily tasks.

CT4. if I did not have access to a desktop computer or laptop.

Intention to Use (IU)

IU1. Assuming I have access to the system, I intend to use it.

IU2. Given that I have access to the system, I predict that I would use it.

\section{Appendix 2. Four test scenarios}

\section{Scenario 1: Resource service}

Princess Ofori is taking four courses this semester. On the bus to school, she wanted to find out whether the courses she has registered this semester has resources available to her.

\section{Checking for available resources}

The following procedures will enable you perform the task of checking for Available Resources.

- Log on to the main application with username (tilly) and password (korkoi).

- Click on the Resource to start the resource service.

- Click on the Available Resource button to view the resources that are available.

After Checking for Available Resources, Princess wanted to download one of the resources onto her mobile device. 
- Select the resource you wish to download.

- Click on the download button. The download dialog box pops up, you can choose to click on yes to download the resource to the default path specified or you can choose the save as option and edit the following parameters: Name of resource, Folder and Location.

- Click on the Yes button to save the resource to the mobile device's "My document folder".

- Return to the main menu.

\section{Scenario 2: Collaboration service}

Joseph Angbormi, Emmanuel Sintim, Jean Paul and John Doe are all in the same group TDT4290 Group 5 and have all decided to meet at Jean Paul's residence to discuss the assignment they are suppose to submit. During the course of the day, Joseph Angbormi was not feeling too well and so decided to send a message to the group that "he is sick and will not be able to come for the discussion".

\section{Sending a group message}

The following procedures will enable Joseph Angbormi send a message to the group members of TDT4290 Group 5.

- Log on to the main application with username (tilly) and password (korkoi).

- Click on the collaboration icon to start the collaboration service.

- Click on the message icon.

- Click on the send message icon.

- Select TDT4290 Group 5 from the group drop down box.

- Type your message and click on the send message button to send the message.

- Return to the main application.

\section{Reading personal message}

John Doe wanted to read the personal messages he has received.

- Log on to the main application with username (tilly) and password (korkoi).

- Click on the collaboration icon to start the collaboration service.

- Click on the message icon.

- Click on the get message icon.

- Select from the menu personal message.

- Select a message and click on the read message to view the full message.

- Return to the main application.

\section{Scenario 3: Follow NTNU and friends on twitter}

Bilal has a twitter account and he wants to follow NTNU updates and his fellows on twitter. There are other various possibilities for him to use twitter for institutional updates available at (http://www.ntnu. no/aktuelt/blogger). He also wants to tweet his friends and followers. He wants to keep in contact with his friends by following the replies and the direct messages of the followers or friends.

@NTNU

@NTNUstudier

@NTNUmedicine

@ Vitenskapmuseet 
@engineering

@imefakultetet

Task 1: (Pre conditions): You must have twitter account or can use test account (...). Go to http://www. ntnu.no/aktuelt/blogger and select the provided links to follow on twitter.

Do the followings:

- Logon to MSIS with username (user1)/password (user).

- Start the twitter application and logon with twitter Id/Password.

- Click the "update" button to refresh the updated tweets.

Task2: Check the replies and direct messages from your followers

- Go to Menu->Replies (press “update" button if replies don't appear).

- Go to Menu->Direct Messages (press "update" button if messages don't appear).

Task3: Send tweets/messages

To send a tweet/message, perform the following steps:

- Go to Menu->Tweet.

- Type your message (message limit is 140 characters) and press Send button.

- Check your tweet: Go to Menu->Timeline.

\section{Scenario 4: Keep yourself update with your favorite RSS and atom feeds}

Hassaan likes instant updates and wants to keep himself updated by subscribing to various news feeds and other favorite feeds such as educational news, weather, sports and blogs. He wants to get news feeds from his university site and on departmental events. He is very social and wants to remain active in the events of various student societies. He loves blogging and wants to follow the updates of his favorite blogs as well. He subscribes to all his favorite feeds and manages them according to his own priorities.

Some NTNU feeds available at (http://www.ntnu.no/aktuelt/blogger) are

- Generelle nyheter fra NTNU.

- Forskning.

- Næringsliv og nyskaping.

- Studier.

- Team NTNUs blogg.

- News - forskningsnyheter påengelsk.

Task 1: Read news feeds

To read the news feeds, perform the following steps

- Start the RSS application from MSIS main application container.

- Open the different news folders/categories.

- Select the news title to read the detail.

- Mark it as Read/Unread using the Menu options.

- Navigate through all categories and news using options available in "Menu".

Task 2: Subscribe new feeds

To subscribe news feeds, perform the following steps.

Pre Condition: The URL of the news feed to which you want to subscribe. For example the URL of NTNU IDI Events is: http://www.idi.ntnu.no/news/rss/events.xml. The feeds can be RSS and ATOM of any version. 
- Select the desired category/folder to which you want to add feed.

- Go to Menu->Add New-> Feed.

- Enter the feed address/URL.

- Change the settings such as "Storage Limit" and "Parent Category" by clicking the Storage and Folder button.

- Go back and check updates.

Task 3: Add new categories of feeds

To add or create new categories of news feeds, do the following steps

- Go to Menu->Add New->Folder and enter the desired title.

- Select the newly created category and follow the steps of Task 2 to add new feeds in this category.

- Go to Menu->Edit Feed Details to edit the detail such as title, URL, storage limit of any selected feed. You can enter the URL directly or select from the given list of RSS feeds.

\section{Appendix 3. The means and standard deviations for each of the items in the survey}

\begin{tabular}{lccc}
\hline & $\mathrm{N}$ & Mean & Std. deviation \\
\hline PU1 & 46 & 4.9348 & 1.32333 \\
PU2 & 46 & 5.7826 & 1.22770 \\
PU3 & 46 & 5.2174 & 1.31509 \\
PU4 & 46 & 5.6522 & 1.21504 \\
PEOU1 & 46 & 5.8478 & 1.44480 \\
PEOU2 & 46 & 5.6957 & 1.11295 \\
PEOU3 & 46 & 4.8913 & 1.56671 \\
PEOU4 & 46 & 5.1304 & 1.55790 \\
TU1 & 46 & 5.3913 & 1.20145 \\
TU2 & 46 & 5.0435 & 1.59104 \\
TU3 & 46 & 6.1957 & 0.98024 \\
TU4 & 46 & 5.7174 & 1.18627 \\
TU5 & 46 & 6.0217 & 1.35793 \\
TU6 & 46 & 5.7609 & 1.35294 \\
PIC1 & 46 & 5.0652 & 1.37279 \\
PIC2 & 46 & 4.3913 & 1.81938 \\
PIC3 & 46 & 4.870 & 1.6139 \\
PIC4 & 46 & 5.2391 & 1.13890 \\
PIC5 & 46 & 4.0000 & 1.80123 \\
CT1 & 46 & 5.8478 & 1.03209 \\
CT2 & 46 & 5.7826 & 1.13359 \\
CT3 & 46 & 6.2826 & 0.83435 \\
CT4 & 46 & 5.8913 & 1.23339 \\
IU1 & 46 & 5.5435 & 1.25974 \\
IU2 & 46 & 5.4783 & 1.14967 \\
Valid N (listwise) & 46 & & \\
\hline & & & \\
\hline
\end{tabular}

\section{References}

[1] R. Agarwal and J. Prasad, A conceptual and operational definition of personal innovativeness in the domain of information technology, Info Sys Research 9 (1998), 204-215.

[2] I. Ajzen, The theory of planned behavior, Organizational Behavior and Human Decision Processes 50 (1991), $179-211$.

[3] I. Ajzen and M. Fishbein, Understanding Attitudes and Predicting Social Behavior, Prentice-Hall Englewood Cliffs, 1980. 
[4] S.H. Andresen, J. Krogstie and T. Jelle, Lab and research activities at wireless trondheim, in: 4th International Symposium on Wireless Communication Systems, 2007, IEEE, Trondheim, Norway, 2007.

[5] M. Asif and J. Krogstie, Mobile student information system, Campus-Wide Information Systems In press (2011).

[6] R. Bagozzi, The legacy of the technology acceptance model and a proposal for a paradigm shift, Journal of the Association for Information Systems 8 (2007), 244-254.

[7] S.J. Barnes, The mobile commerce value chain: Analysis and future developments, International Journal of Information Management 22 (2002), 91-108.

[8] R.C. Basole, The value and impact of mobile information and communication technologies, in: IFAC Symposium on Analysis, Modelling \& Evaluation of Human-Machine Systems, Atlanta GA, USA, 2004.

[9] I. Benbasat and H. Barki, Quo vadis TAM, Journal of the Association for Information Systems 8 (2007), 211-218.

[10] I. Benbasat and R.W. Zmud, Empirical research in information systems: The practice of relevance, MIS Q 23 (1999), 3-16.

[11] P.M. Bentler, On the fit of models to covariances and methodology to the Bulletin, Psychological Bulletin 112 (1992), 400.

[12] H. Bouwman and L. van de Wijngaert, Coppers context, and conjoints: A reassessment of TAM, Journal of Information Technology 24 (2009), 186-201.

[13] C. Carlsson, J. Carlsson, K. Hyvonen, J. Puhakainen and P. Walden, Adoption of mobile devices/services - searching for answers with the UTAUT, in: Proceedings of the 39th Annual Hawaii International Conference on System Sciences Volume 06, IEEE Computer Society, 2006, pp. 132.131.

[14] S.E. Chang and Y.-H.V. Pan, Exploring factors influencing mobile users' intention to adopt multimedia messaging service, Behaviour \& Information Technology 30 (2011), 659-672.

[15] L.-D. Chen, A model of consumer acceptance of mobile payment, Int J Mob Commun 6 (2008), 32-52.

[16] C. Clark, Coming attraction, Wireless Review 17 (2000), 12-16.

[17] E. Constantinides, The 4S web-marketing mix model, Electronic Commerce Research and Applications 1 (2002), 57-76.

[18] H. Dai and P.C. Palvi, Mobile commerce adoption in China and the United States: A cross-cultural study, SIGMIS Database 40 (2009), 43-61.

[19] F.D. Davis, Perceived usefulness, perceived ease of use and user acceptance of information technology, MIS Quarterly 13 (1989), 319-340.

[20] F.D. Davis, R.P. Bagozzi and P.R. Warshaw, User acceptance of computer technology: A comparison of two theoretical models, Manage Sci 35 (1989), 982-1003.

[21] W. DeLone and E. McLean, Information systems success: The quest for the dependent variable, Information Systems Research 3 (1992).

[22] A.K. Dey, Understanding and using context, Personal Ubiquitous Comput 5 (2001), 4-7.

[23] S. Figge, Situation-dependent services - a challenge for mobile network operators, Journal of Business Research 57 (2004), 1416-1422.

[24] M. Fishbein and I. Ajzen, Belief, Attitude, Intention and Behavior: An Introduction to Theory and Research, AddisonWesley, 1975.

[25] S. Gao and J. Krogstie, The importance of context towards mobile services adoption, in: The Fourth International Conference on Mobile Ubiquitous Computing, Systems, Services and Technologies (Ubicomm 2010), IARIA Press, Florence, Italy, 2010.

[26] S. Gao, J. Krogstie and P.A. Gransæther, Mobile services acceptance model, in: Proceedings of ICHIT, IEEE Computer Society, 2008 .

[27] S. Gao, J. Krogstie and K. Siau, Developing an instrument to measure the adoption of mobile services, Mobile Information Systems Journal 7 (2011), 45-67.

[28] D. Gefen, TAM or just plain habit: A look at experienced. Online shoppers, Journal of End User Computing 15 (2003), $1-13$.

[29] D. Gefen, E. Karahanna and D.W. Straub, Trust and TAM in online shopping: An integrated model, MIS Quarterly 27 (2003), 51-90.

[30] M. Hassenzahl and N. Tractinsky, User experience - a research agenda, Behaviour \& Information Technology 25 (2006), 91-97.

[31] A.-C. Haugstvedt and J. Krogstie, Mobile augmented reality for cultural heritage: A technology acceptance study, in, 2012, pp. 247-255.

[32] H.V.D. Heijden, Factors influencing the usage of websites: the case of a generic portal in The Netherlands, Information \& Management 40 (2003), 541-549.

[33] H.V.D. Heijden, User acceptance of hedonic information systems, MIS Quarterly 28 (2004), 695-704.

[34] D.L. Hoffman, T.P. Novak and M. Peralta, Building consumer trust online, Commun ACM 42 (1999), 80-85.

[35] S.-J. Hong and K.Y. Tam, Understanding the adoption of multipurpose information appliances: The case of mobile data services, Info Sys Research 17 (2006), 162-179. 
[36] S.-J. Hong, J.Y.L. Thong and K.Y. Tam, Understanding continued information technology usage behavior: A comparison of three models in the context of mobile internet, Decision Support Systems 42 (2006), 1819-1834.

[37] R.P. Horton, T. Buck, P.E. Waterson and C.W. Clegg, Explaining intranet use with the technology acceptance model, Journal of Information Technology 16 (2001), 237-249.

[38] J. Hosbond and P. Nielsen, Mobile systems development: A literature review, in: Designing Ubiquitous Information Environments: Socio-Technical Issues and Challenges, C. Sørensen, Y. Yoo, K. Lyytinen and J. DeGross, eds, Springer Boston, 2005, pp. 215-232.

[39] D. Iacobucci, Structural equations modeling: Fit Indices, sample size, and advanced topics, Journal of Consumer Psychology 20 (2010), 90-98.

[40] R.A. Johnson and M.A. Hignite, Applying the technology acceptance model to the WWW, Academy of Information and Management Sciences Journal 3 (2000), 130-142.

[41] J. Krogstie, Requirements engineering for mobile information systems, in: the Seventh International Workshop on Requirements Engineering: Foundations for Software Quality (REFSQ'01), Interlaken, Switzerland, 2001.

[42] J. Krogstie, Bridging research and innovation by applying living labs for design science research, in: Nordic Contributions in IS Research, C. Keller, M. Wiberg, P. Ågerfalk and J.Z.E. Lundström, eds, Springer Berlin Heidelberg, 2012, pp. 161-176.

[43] Y.-F. Kuo and S.-N. Yen, Towards an understanding of the behavioral intention to use 3G mobile value-added services, Comput Hum Behav 25 (2009), 103-110.

[44] A.L. Lederer, D.J. Maupin, M.P. Sena and Y. Zhuang, The technology acceptance model and the World Wide Web, Decis Support Syst 29 (2000), 269-282.

[45] T. Lee and J. Jun, Contextual perceived usefulness? Toward an understanding of mobile commerce acceptance, in: Proceedings of the International Conference on Mobile Business, IEEE Computer Society, 2005.

[46] P. Legris, J. Ingham and P. Collerette, Why do people use information technology? A critical review of the technology acceptance model, Inf Manage 40 (2003), 191-204.

[47] J. Lu, J.E. Yao and C.-S. Yu, Personal innovativeness, social influences and adoption of wireless Internet services via mobile technology, The Journal of Strategic Information Systems 14 (2005), 245-268.

[48] J. Lu, C.-S. Yu, C.Y. Liu and J.E., Technology acceptance model for wireless Internet, Internet Research 13 (2003), 206-222.

[49] P. Luarn and H.-H. Lin, Toward an understanding of the behavioral intention to use mobile banking, Computers in Human Behavior 21 (2005), 873-891.

[50] N. Mallat, M. Rossi, V.K. Tuunainen and A. Oorni, The impact of use situation and mobility on the acceptance of mobile ticketing services, in: Proceedings of the 39th Annual Hawaii International Conference on System Sciences - Volume 02, IEEE Computer Society, 2006.

[51] E. Mao, M. Srite, J.B. Thatcher and O. Yaprak, A research model for mobile phone service behaviors: empirical validation in the US and Turkey, Journal of Global Information Technology Management 8 (2005), 7-28.

[52] R. Mayer, J. Davis and D. Schoorman, An integrative model of organizational trust, The Academy of Management Review 20 (1995), 709-734.

[53] S.P. Moe, Design and Evaluation of a User-Centric Information System, Master Thesis, Norwegian University of Science and Technology, 2009.

[54] S. Moss, H. Prosser, H. Costello, N. Simpson, P. Patel, S. Rowe, S. Turner and C. Hatton, Reliability and validity of the PAS-ADD checklist for detecting psychiatric disorders in adults with intellectual disability, Journal of Intellectual Disability Research 42 (1998), 173-183.

[55] H. Nysveen, P. Pedersen and H. Thorbjørnsen, Intentions to use mobile services: Antecedents and cross-service comparisons, Journal of the Academy of Marketing Science 33 (2005), 330-346.

[56] D.J. Ozer, Quantitative methods in psychology, (1985).

[57] P.A. Pavlou, Consumer acceptance of electronic commerce: Integrating trust and risk with the technology acceptance model, Int J Electron Commerce 7 (2003), 101-134.

[58] E.J. Pedhazur, Multiple-Regression in Behavioral Research: Explanation and Prediction, Wadsworth Pub Co, 1997.

[59] J.P. Robinson, P.R. Shaver and L.S. Wrightsman, Criteria for scale selections and evaluation, Academic Press, San Diego, CA, 1991.

[60] E.M. Rogers, The Diffusion of Innovations, Free Press, New York, 1995.

[61] S. Sarker and J.D. Wells, Understanding mobile handheld device use and adoption, Commun ACM 46 (2003), 35-40.

[62] K. Siau and Z. Shen, Building customer trust in mobile commerce, Commun ACM 46 (2003), 91-94.

[63] S. Taylor and P. Todd, Assessing IT usage: The role of prior experience, MIS Q 19 (1995), 561-570.

[64] S. Taylor and P.A. Todd, Understanding information technology usage: A test of competing models, Information Systems Research 6 (1995), 144-176.

[65] R.L. Thompson, C.A. Higgins and J.M. Howell, Personal computing: Toward a conceptual model of utilization, MIS $Q$ 15 (1991), 125-143. 
[66] A.M. Townsend, S.M. Demarie and A.R. Hendrickson, Desktop video conferencing in virtual workgroups: Anticipation, system evaluation and performance, Information Systems Journal 11 (2001), 213-227.

[67] N. Tractinsky, Aesthetics in information technology: Motivation and future research directions, Human-Computer Interaction and Management Information Systems: Foundations (2006), 330-347.

[68] V. Venkatesh, Determinants of perceived ease of use: Integrating control, intrinsic motivation, and emotion into the technology acceptance model, Info Sys Research 11 (2000), 342-365.

[69] V. Venkatesh, M.G. Morris, G.B. Davis and F.D. Davis, User acceptance of information technology: Toward a unified view, MIS Quarterly 27 (2003), 425-478.

[70] H. Wold, Systems Analysis by Partial Least Squares, Martinus Nijhoff, 1985.

[71] J.-H. Wu and S.-C. Wang, What drives mobile commerce? An empirical evaluation of the revised technology acceptance model, Inf Manage 42 (2005), 719-729.

[72] Z. Xu and Y. Yuan, What is the influence of context and incentive on mobile commerce adoption? A case study of a gpsbased taxi dispatching system, in: Proceedings of the International Conference on the Management of Mobile Business, IEEE Computer Society, 2007.

[73] K.C.C. Yang, Exploring factors affecting the adoption of mobile commerce in Singapore, Telemat Inf 22 (2005), 257277.

[74] D. Zhang, Delivery of personalized and adaptive content to mobile devices: a framework and enabling technology, Communications of the Association for Information Systems 12 (2003), 183-202.

[75] M. Ziefle, The influence of user expertise and phone complexity on performance, ease of use and learnability of different mobile phones, Behaviour \& Information Technology 21 (2002), 303-311.

Shang Gao is Associate Professor at School of Business Administration at the Zhongnan University of Economics and Law, China. He obtained his PhD (2011) in information systems from the Norwegian University of Science and Technology (NTNU), and his MSc (2006) in Engineering and Management of Information Systems from the Royal Institute of Technology (KTH), Sweden. His research interests include mobile information systems, technology diffusion, business process modeling, and information systems modeling. He has published more than 20 refereed papers in journals, books and archival proceedings since 2006.

John Krogstie (1967) received a M.Sc. in Information Systems from IDT, NTH (IDI, NTNU predecessor) in 1991 and has a $\mathrm{Ph} . \mathrm{D}$. in Information Systems (IDI, NTNU) from 1995 with the title 'Conceptual modelling for information systems support in Organisations'. He was employed as a manager in Accenture 1991-2000, where he worked extensively with methodology development, customisation, deployment and improvement both for a multitude of Accenture clients and internally. In 2000-2005 he was employed by SINTEF as senior researcher, and was a senior advisor at SINTEF 2005-2008. Since 2005 he has been Professor at IDI, NTNU, focusing on enterprise and process modelling, quality of models and modelling languages, eGovernment and virtual organizations and ecosystems, and mobile and ubiquitous information systems. Krogstie leads the cross-disciplinary thematic area of ICT at NTNU, which includes programs on eGovernment, ICT and learning, and health informatics, and is in this role Vice-Dean of the IME faculty. He also lead the Wireless Trondheim Living Lab, which are member of ENoLL, European network of living labs http://www.openlivinglabs.eu, with a focus on research and user-driven innovation on mobile and ubiquitous applications and services. Krogstie is Chair of IFIP WG 8.1 on Design and Evaluation of Information Systems (2010-2015, vice-chair 2004-2009) John Krogstie has published around 200 refereed papers in journals, books and archival proceedings since 1991. Current (May 2013) H-index is 25. G-index 40. See http://www.idi.ntnu.no/ krogstie/ for more information.

Keng Siau is the Chair of the Department of Business and Information Technology at the Missouri University of Science and Technology. Professor Siau is the Editor-in-Chief for the Journal of Database Management, North America Regional Editor for the Requirements Engineering journal, and Co-Editor-in-Chief for the Advances in Database Research series. He is the Vice President of Education for the Association for Information Systems and serves on the Board of Partnership for Advancing Computing Education (PACE). Professor Siau has more than 250 academic publications. According to the ISI Web of Science and Google Scholar, he has more than 1700 and 5000 citation counts respectively. His h-index, according to Harzing's Publish or Perish, is 37. In 2011, he was ranked as one of the top researchers in his field based on h-index and productivity rate. In 2006, he was ranked as one of the top ten e-commerce researchers in the world. In the same year, the citation count for his paper "Building Customer Trust in Mobile Commerce" is ranked in the top 1\% within the field as reported by Essential Science Indicators. Professor Siau has received numerous teaching, research, and service awards. He is a recipient of the prestigious International Federation for Information Processing (IFIP) Outstanding Service Award in 2006, the IBM Faculty Awards in 2006 and 2008, and the IBM Faculty Innovation Award in 2010. 

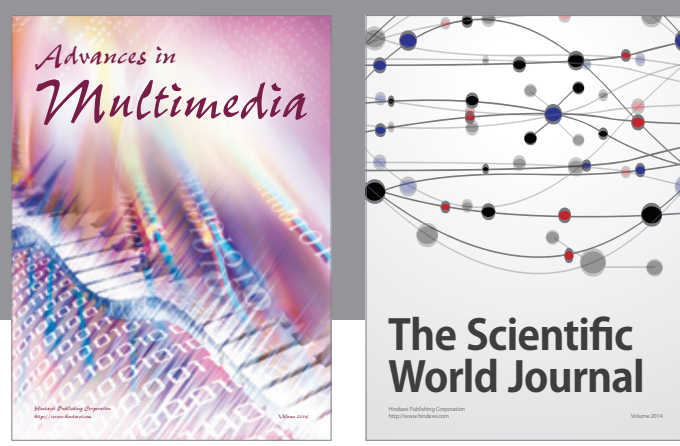

The Scientific World Journal
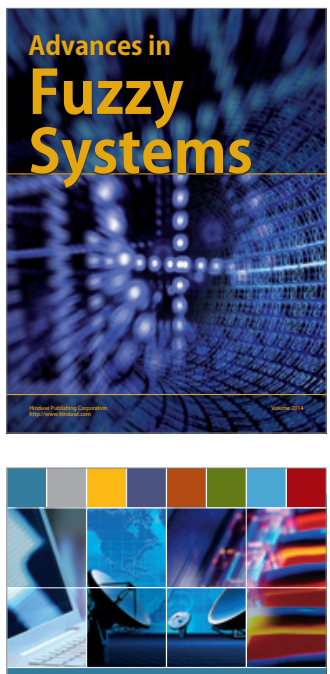

Computer Networks and Communications
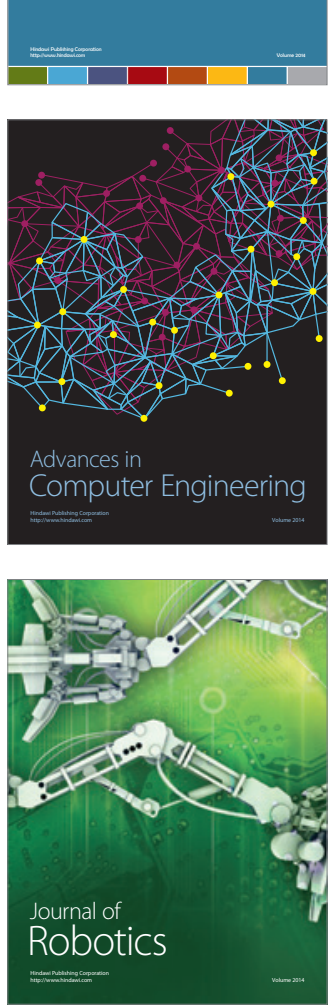
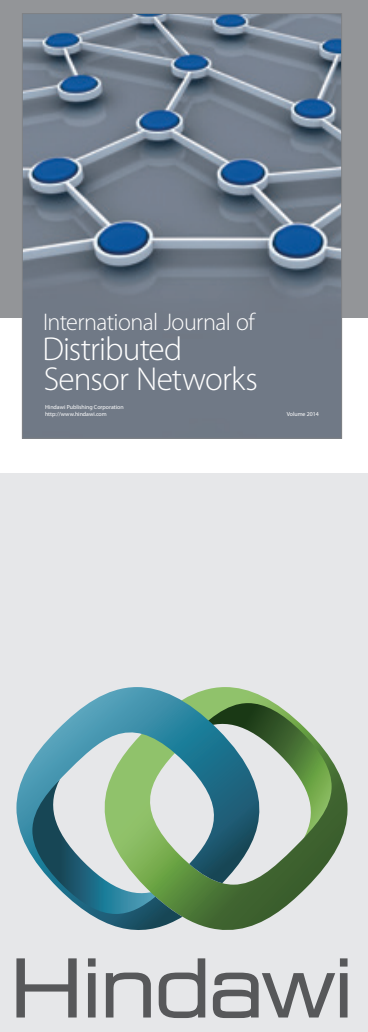

Submit your manuscripts at

http://www.hindawi.com
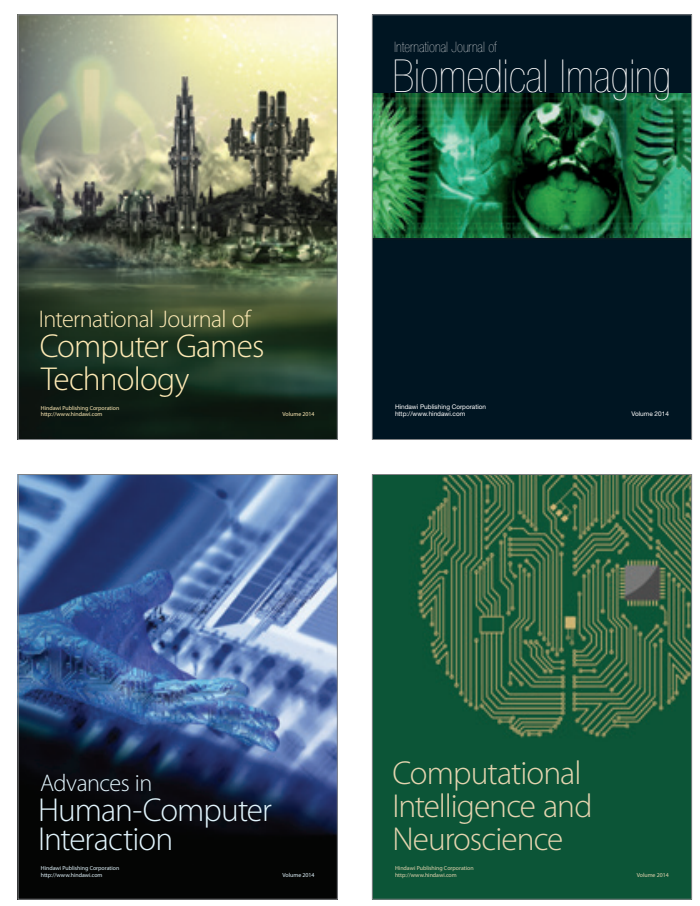
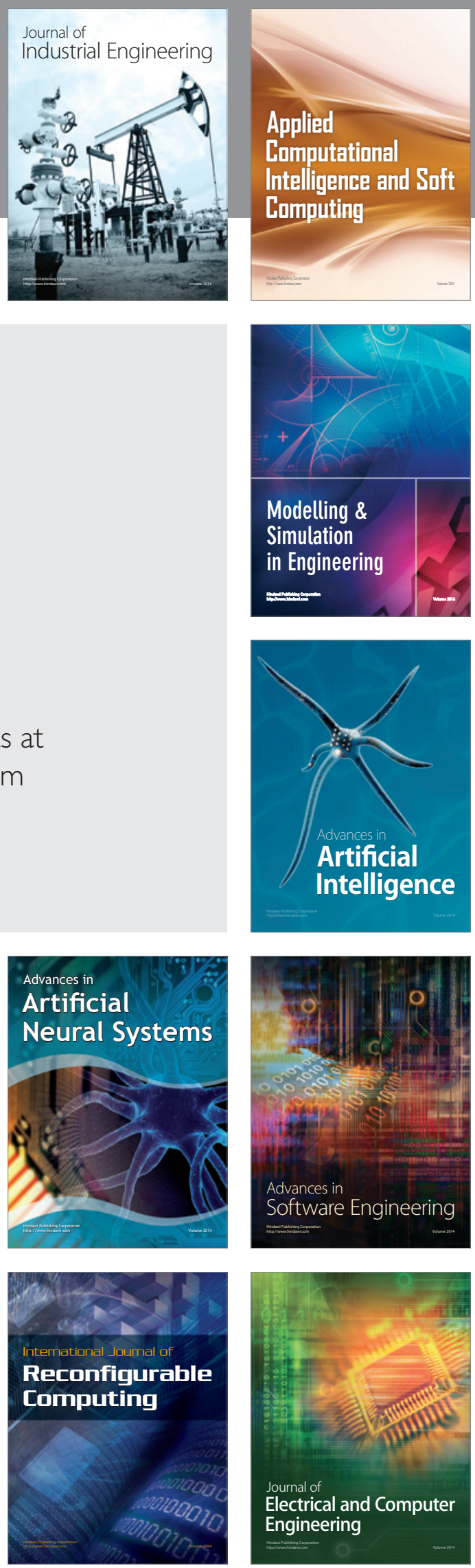